\title{
Molecular Dynamics simulations of supercritical ammonia and metal-ammonia solutions
}

\author{
S.Hannongbua ${ }^{1}$, M.Kiselev ${ }^{2}$, K. Heinzinger ${ }^{3}$ \\ 1 Department of Chemistry, Faculty of Science, Chulalongkorn University, \\ Bangkok 10330, Thailand \\ 2 Institute of Solution Chemistry, Russian Academy of Sciences, \\ 153045 Ivanovo, Russia \\ 3 Max-Planck-Institut für Chemie (Otto-Hahn-Institut), \\ D-55020 Mainz, Germany
}

Received March 3, 2000

\begin{abstract}
The results of Molecular Dynamics simulations of supercritical ammonia are reported for the first time. Qualitative agreement is found with neutron diffraction studies, the only experimental evidence on the structure of supercritical ammonia, so far. Based on the experiences with aqueous electrolyte solutions, it is discussed how the potentials describing ion-ammonia interactions in dilute and concentrated metal-ammonia solutions at subcritical conditions have to be modified for supercritical simulations.
\end{abstract}

Key words: Molecular Dynamics simulation, aqueous electrolyte solutions, supercritical ammonia, metal-ammonia solutions

PACS: $61.20 . J, 61.20 . \mathrm{Qg}, 71.15 . P d$

Dedicated to Professor Igor Yukhnovskii on the occasion of his 75th birthday.

\section{Introduction}

There is an increasing interest in the investigation of supercritical electrolyte solutions. The state of art of the simulation of water and aqueous solutions under supercritical conditions can be found in the recent review by Chialvo and Cummings [1]. Ammonia is also of interest as a solvent. The first, and so far the only, neutron diffraction study of supercritical ammonia was reported by Bausenwein et al. [2]. They measured pure ammonia at $449 \mathrm{~K}$ and four different densities. They analyzed the experimental data by the Reverse Monte Carlo method (RMC) and compared the results for the three radial distribution functions (RDF) with those from 
calculations with the site-site-Ornstein-Zernicke (SSOZ) equation with the HNC closure by employing various potential models available in the literature.

It is expected that MD simulations lead to more reliable results than the SSOZ calculations. Therefore, we have performed simulations with the $\mathrm{NH}_{3}$ model employed for the simulation of $\mathrm{Li}^{+}$-liquid ammonia solutions some time ago [3]. The same model was also used in the SSOZ calculations mentioned above and has led to a reasonable agreement with the experimental results, at least at the higher densities. It will be interesting to see how much the MD simulations differ from those of the SSOZ calculations under supercritical conditions.

In the next chapter the details of the first simulations of supercritical pure ammonia will be given and preliminary results will be presented. In the following chapter the solvation shell structures of various alkali and alkaline earth ions in ammonia will be compared with those in aqueous solutions, all derived from simulations with a single ion under subcritical conditions. From this comparison together with the results for supercritical aqueous solutions, the applicability of the ion-ammonia potentials, employed so far, for simulations of supercritical solutions will be discussed.

From simulations of concentrated $\mathrm{Li}^{+}$-ammonia solutions, cluster formation between solvated $\mathrm{Li}^{+}$has been deduced [4]. In these simulations the pseudopotential theory has been employed. In this way the electrons do not have to be treated explicitly and classical simulations can be performed [5]. The applicability of this theory to supercritical concentrated metal-ammonia solutions will be discussed.

\section{Simulations of supercritical pure ammonia}

\subsection{Details of the simulations}

The three simulations, the results of which are reported here, were performed for an NVT ensemble consisting of 215 flexible ammonia molecules. The ammonia model employed has been taken from [3]. For the subcritical simulation a temperature of $220 \mathrm{~K}$ was chosen. With a density of $0.71 \mathrm{~g} \mathrm{~cm}^{-3}$, a pressure of $20 \mathrm{MPa}$ results. For both simulations at supercritical conditions, the temperature was set to $430 \mathrm{~K}$, with densities of 0.53 and $0.73 \mathrm{~g} \mathrm{~cm}^{-3}$ pressures of 20 and $400 \mathrm{MPa}$ resulted, respectively. The sidelength of the basic cube was about $20 \AA$. The time step length was chosen to be 0.125 fs. The simulations extended over $10 \mathrm{ps}$ each. For further details the reader is referred to $[6]$.

\subsection{Preliminary results and comparison with experimental data}

The N-N and N-H RDFs from two simulations at supercritical conditions are compared in figure 1 with one of liquid ammonia at $220 \mathrm{~K}$ and a density of $0.71 \mathrm{~g} \mathrm{~cm}^{-3}$ [6]. The subcritical simulation agrees favourably with a former simulation with the same ammonia model at $235 \mathrm{~K}$ and a density of $0.690 \mathrm{~g} \mathrm{~cm}^{-3}$ [3].

It can be seen from figure 1 that at the higher temperature, the height of the first peak is lower and broadened for all RDFs. Also the other maxima and minima 


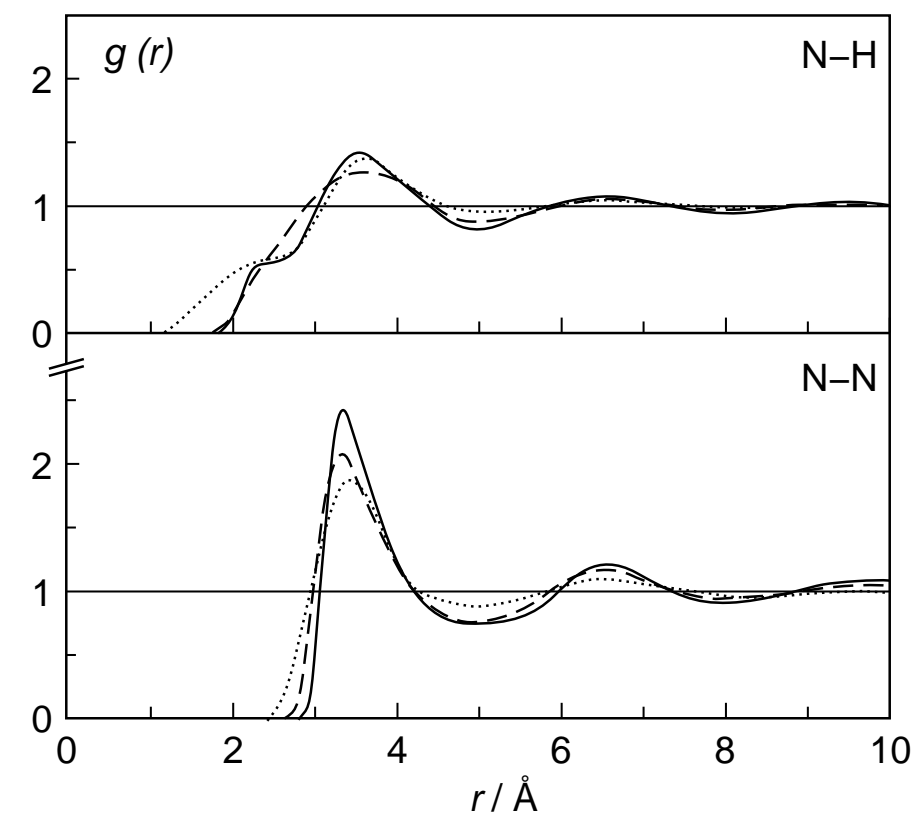

Figure 1. Nitrogen-nitrogen and nitrogen-hydrogen radial distribution functions from simulations of supercritical ammonia. The full, dashed, and dotted lines refer to temperatures of 220,430 , and $430 \mathrm{~K}$ and densities of $0.71,0.73$, and $0.53 \mathrm{~g} \mathrm{~cm}^{-3}$, respectively.

are less pronounced. The effect is more significant for the N-N when compared with the N-H RDFs as the latter ones are already very broad even at a low temperature.

Furthermore, the positions of the first maxima remain unchanged with the increase in temperature at a constant density. If the temperature is kept constant, but the density decreased, then the positions of the first maxima shift to higher distances while the positions of all other maxima and minima seem to be unchanged. The shoulder at the long distance side of the first peak in the N-N RDF - discussed before in all simulations of pure ammonia - can be found even under supercritical conditions. All RDFs extend at the high temperature to shorter distances, more pronounced at the lower than at the higher density.

To the best of our knowledge there is no other simulation and only one experimental investigation of supercritical ammonia for comparison. Bausenwein et al. [2] performed neutron diffraction measurements at $449 \mathrm{~K}$ and four different densities ranging from $0.318-0.700 \mathrm{~g} \mathrm{~cm}^{-3}$. The authors calculated from the intermolecular total RDF the partial ones by RMC simulations and compared them with the results from SSOZ calculations by employing various ammonia models from the literature, one of which was the model used in this work, too.

There are some differences in the positions and the heights of the first maxima in the RDFs between the simulation data presented in figure 1 and the SSOZ calculations. This is not surprising as it is well known that the employment of the SSOZ method for hydrogen bonded liquids is connected with some difficulties.

There are also some small differences between the positions and the heights of the first maxima of all RDFs between simulation results and neutron diffraction data. 
But the tendencies of the changes in going from sub- to supercritical conditions are the same: At a constant density the heights of the first peaks decrease and broaden with the increasing temperature while the positions remain unchanged. At a constant temperature and a decreasing density, the positions shift to larger distances and the heights decrease for the N-N RDFs but increase for the N-H RDFs. This means that even under supercritical conditions the hydrogen bonding increases with a decreasing density.

A quantitative comparison between simulated and experimental results is not possible because the partial RDFs derived from the total RDF by RMC show very broad and noisy first peaks. In addition, it has to be kept in mind that there exists a problem with the uniqueness of the RMC method.

The qualitative agreement between simulation and experiment indicates - at least at this stage - that the ammonia model employed in the simulations does not lead to serious discrepancies with the experiment. Therefore, it is justified to use this model for further simulations of supercritical ammonia as well as metal-ammonia solutions for the time being. The potentials necessary to describe the ion-ammonia interactions are discussed in the following chapter.

\section{Supercritical aqueous electrolyte and metal-ammonia solutions}

With the beginning of this decade the simulation of metal-liquid ammonia solutions developed in three different directions:

1) The extension of single ion simulations to various alkali and alkaline earth metals by neglecting the electron. The investigation of many-body effects in the ion-ammonia potentials.

2) Quantum simulations with electron concentrations of up to 9 MPM (mole percent of metal) where the positive ions are either treated as neutralizing background or, at a high concentration, the $\mathrm{Li}^{+}$are considered explicitly.

3) The simulation of concentrated $\mathrm{Li}^{+}$-ammonia solutions with concentrations up to 20 MPM through the application of the pseudopotential theory. Renormalized effective interatomic potentials are derived in this way, so that the electrons can be excluded from explicit consideration and classical simulation methods can be employed.

In the preceding report these three approaches towards the understanding of the structural and dynamical properties of metal-liquid ammonia solutions have been discussed in some detail [7]. Now it has to be checked whether the experience with the potentials used in these simulations justifies their employment also in simulations of supercritical metal-ammonia solutions.

\subsection{Single ion simulations}

It is difficult to settle the question of the need of many-body potentials for the correct description of the structure of ionic solvation shells in metal-ammonia 
Table 1. Ion-nitrogen and ion-oxygen first neighbour distances and solvation numbers as deduced from simulations for five cations. The temperatures for the ammonia and the aqueous solutions were about $240 \mathrm{~K}$ and $300 \mathrm{~K}$, respectively.

\begin{tabular}{lllllll}
\hline Ion & $\mathrm{r}_{\max }^{\mathrm{IN}}$ & $\mathrm{n}\left(\mathrm{r}_{\min }\right)$ & Reference & $\mathrm{r}_{\max }^{\mathrm{IO}}$ & $\mathrm{n}\left(\mathrm{r}_{\min }\right)$ & Reference \\
\hline $\mathrm{Li}$ & 2.20 & $6 ; 4$ & {$[9] ;[10]$} & 2.13 & 6.1 & {$[11]$} \\
$\mathrm{Na}$ & 2.42 & 7 & {$[12]$} & 2.36 & 6.5 & {$[13]$} \\
$\mathrm{K}$ & 2.88 & 7 & {$[14]$} & 2.80 & 7.8 & {$[15]$} \\
$\mathrm{Mg}$ & 2.18 & 6 & {$[16]$} & 2.00 & 6 & {$[17]$} \\
$\mathrm{Ca}$ & 2.53 & 9 & {$[18]$} & 2.39 & 9.2 & {$[19]$} \\
\hline
\end{tabular}

solutions because of a lack of experimental data which in turn is a result of the temperature range of interest. The simulation results (mainly positions of the first maxima of the ion-nitrogen RDFs and the coordination numbers) have already been collected in [7] and will not be discussed here again. An indication of the reliability of the results can be found by comparison with the hydration shells of those ions in aqueous solutions where a large amount of experimental evidence is available, mainly from X-ray and neutron diffraction measurements. In table I the first neighbour ion-nitrogen and ion-oxygen distances and the coordination numbers, defined by the integration up to the first minimum of the corresponding RDFs, are collected for five cations. All results presented are from simulations. In the case of aqueous solutions the simulation results are found to be in good agreement with experimental data [8].

The ion-nitrogen first neighbour distances are found to be slightly larger than the ion-oxygen ones, while the solvation numbers seem to be quite similar, except for the lithium ion, where some simulations lead to a value of four. The comparison of the solvation number of $\mathrm{Li}^{+}$in ammonia with that in water also strongly favours a value of six. All pair potential simulations of various lithium halide solutions lead to a hydration number of six in agreement with neutron diffraction studies with isotopic substitution [20], which are expected to provide the most reliable data on RDFs and, with it, on coordination numbers. It is very difficult to imagine why there should be only four ammonia but six water molecules in the first solvation shell of $\mathrm{Li}^{+}$although the $\mathrm{Li}^{+}-\mathrm{N}$ distance is by about $0.1 \AA$ larger than the $\mathrm{Li}^{+}-\mathrm{O}$ one. $\mathrm{A}$ final answer cannot be derived from the simulations at this stage.

After it has been demonstrated in the preceding chapter that neat supercritical ammonia can be simulated reliably, the question arises about supercritical metalammonia solutions. So far no reports can be found in the literature. But there are reports on simulations of supercritical aqueous solutions. So far only three cations have been investigated. Driesner et al. [21] simulated a $\mathrm{Na}^{+}$in 2177 water molecules, while Lee and Cummings [22] reported on $\mathrm{Li}^{+}, \mathrm{Na}^{+}$, and $\mathrm{Cs}^{+}$.

The effect of the supercriticality on the structure of the hydration shell of the cations in water can be described in short: The first neighbour ion-oxygen distances do not change significantly with temperature or density. The hydration numbers 
also do not change with temperature but decrease almost linearly with density. These results have been achieved with the SPC/E model for water and ion-water potentials which were taken from earlier simulations of aqueous electrolyte solutions under ambient conditions, where simulations have led to the results in agreement with the experimental data and also a simulation of a LiI solution at a constant density and temperatures up to $500 \mathrm{~K}$ [23].

Unfortunately, there is no direct experimental evidence that the transfer of ionwater potentials from ambient to supercritical conditions is justified for the ions given in table 1 . But the tendency that there is only a slight change in the first neighbour distances with temperature and a decrease in the hydration number with a decreasing density has been confirmed by neutron diffraction and EXAFS measurements for $\mathrm{Ni}^{2+}, \mathrm{Ag}^{+}, \mathrm{Rb}^{+}$, and $\mathrm{Cl}^{-}$[21]. Another indirect way to learn about the reliability of the potentials is the comparison of the simulated molar conductances for very dilute aqueous solutions with experimental data for supercritical alkali halide solutions. The molar conductances from the single ion simulations have to be added up for a comparison with the experimental data from the salt solutions. Possible ion pair formations might result in errors; but they are expected to be small because of the very dilute solutions in the experiment, too. Good agreement has been found for $\mathrm{NaBr}$ and $\mathrm{CsBr}$, while there is a significant discrepancy in the case of the $\mathrm{LiCl}$ solution which has to be attributed to the unclear conductance of $\mathrm{Li}^{+}[22]$. From the general agreement in the conductances it has been concluded that the hydration shell structures are also correct, at least qualitatively. The discrepancy for $\mathrm{Li}^{+}$ has been explained by the disagreement with the hydration number of $\mathrm{Li}^{+}$. From the supercritical simulations, an almost density independent value of four follows while from neutron diffraction studies with isotopic substitution clearly a hydration number for $\mathrm{Li}^{+}$of six results at ambient conditions.

In spite of this inconsistency one may conclude that in the case of aqueous electrolyte solutions the use of pair potentials, which have been successfully employed in the simulations at ambient conditions, do not lead to a significant disagreement with experiments in the case of supercritical solutions. Based on this qualitative agreement, it seems to be justified to use the pair potentials employed in single ion metal-ammonia simulations also for supercritical solutions, at least for the time being. In the next paragraph the problem of the potentials for the use in concentrated supercritical metal-ammonia solutions will be investigated.

\subsection{Concentrated metal-ammonia solutions}

Scientifically more interesting than single ion studies are the concentrated metalammonia solutions. It has been demonstrated that classical simulations can be performed without taking into account the electrons explicitly by employing the pseudopotential theory [5]. Then, the total potential describing effective site-site interactions is given by

$$
V_{\mathrm{tot}}^{i j}(R)=V_{\mathrm{dir}}^{i j}(R)+V_{\text {ind }}^{i j}(R),
$$




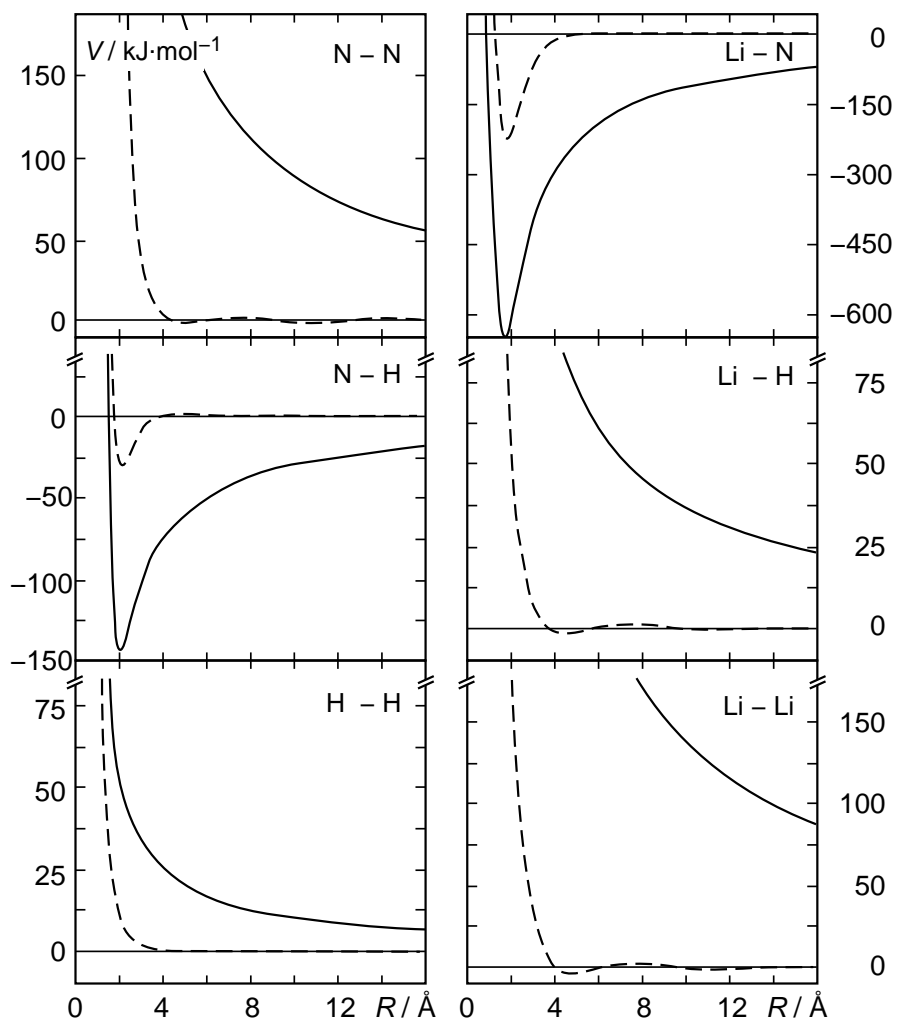

Figure 2. Site-site potentials for the six different interactions in the 11.64 MPM lithium-liquid ammonia solution at a temperature of $240 \mathrm{~K}$. The full and dashed lines denote the direct and the total potential, respectively.

where $V_{\text {dir }}^{i j}(R)$ is the potential for the direct interactions, the same as used in the single ion simulations (preceding chapter), and $V_{\text {ind }}^{i j}(R)$ is caused by free electrons and derived within the pseudopotential theory [5], [24]. $R$ denotes the distance between two sites $i$ and $j$ belonging to different molecules or between a metal ion and an ammonia molecule site. In principle the pseudopotential theory works well if electron solvation does not occur and the metal-ammonia solution behaves like a liquid metal. As it is to be expected that in a certain range of metal concentrations the electrons are only weakly solvated [25], this situation is approximately realized and the pseudopotential theory can be employed for the metal-ammonia solutions.

With this approach, a 11.64 MPM lithium-ammonia solution was simulated. In this MC calculation the basic cube contained $135 \mathrm{Li}^{+}$and $1025 \mathrm{NH}_{3}$ molecules. With an experimental density of $0.554 \mathrm{~g} / \mathrm{cm}^{3}$ a sidelength of the periodic cube of $35.89 \AA$ resulted. For the direct contributions to the total potential a rigid version of the ammonia model described in [3] was employed while new ab initio calculations were performed for the $\mathrm{Li}^{+}-\mathrm{Li}^{+}$and the $\mathrm{Li}^{+}-\mathrm{NH}_{3}$ interactions [4].

In figure 2 the total potentials for the six site-site interactions in the $\mathrm{Li}^{+}-\mathrm{NH}_{3}$ solution as well as the direct contributions are depicted. The indirect contributions calculated from the pseudopotential theory result in a strong screening of the Coulomb interactions in all site-site potentials. It is expected from these now much 
weaker site-site interactions that the polarizibility effect becomes much less important which means, of course, that problems with the many-body interactions, as discussed in the single ion case [7], are much less relevant and need not be considered in first approximation in the concentrated metal-ammonia solutions. It is interesting to note that the consequences of the screening of both, Coulombic attraction and repulsion, leaves the overall ammonia-ammonia and lithium-ammonia potentials almost unchanged as can be seen from figure 3 .

A more detailed analysis of the configurations resulting from the MC calculation shows that the partial RDFs can only be understood by the formation of clusters [4], where $33 \%$ of all $\mathrm{NH}_{3}$ belong to the bulk. From the remaining $67 \%$ of the molecules $55 \%$ are coordinated to one $\mathrm{Li}^{+}$and $12 \%$ simultaneously to two $\mathrm{Li}^{+}$. These data are consistent with the various partial RDFs and their running integration numbers only if we assume that clusters are formed as shown in figure 4. The following distribution of the clusters results: about $35 \%$ of the solvated $\mathrm{Li}^{+}$are not connected, $10 \%$ have one (a), $15 \%$ have two (b), and $40 \%$ have three ammonia molecules in common [4].

Different from the single ion case there is no possibility to compare with aqueous electrolyte solutions in going to the supercritical solution because the electrons cannot be neglected any longer. In addition, there are only results reported for a 1 molal aqueous $\mathrm{NaCl}$ solution [21] while the concentrations of interest here are of the order of $10 \mathrm{MPM}$. The result is very similar to the single ion case. The first neighbour $\mathrm{Na}-\mathrm{O}$ distance remains in the limits of statistical uncertainty unchanged, while the hydration number decreases slightly with increasing tempera-

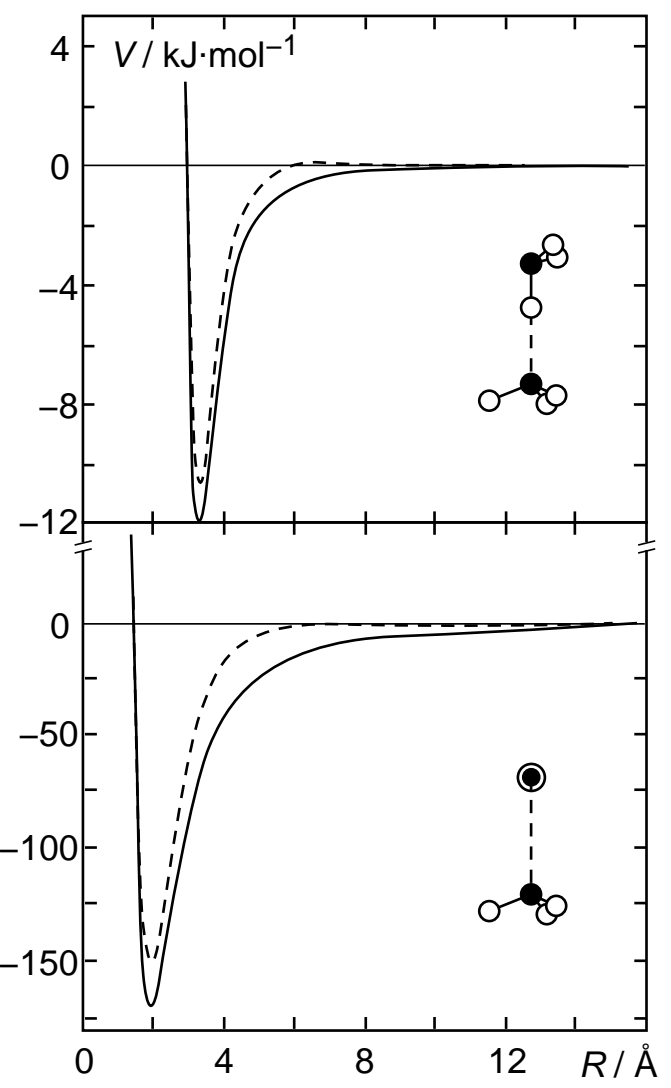

Figure 3. Ammonia-ammonia (top) and lithium-ammonia (bottom) pair potentials as a function of nitrogennitrogen and lithium-nitrogen distances for orientations as shown in the insertions. The full and dashed lines refer to the direct and the total potential, respectively. ture but decreases strongly with decreasing density. The small hydration number of $\mathrm{Na}^{+}$at ambient conditions of 4.8 compared with 6 for $\mathrm{Li}^{+}$is explained by a significant amount of ion pairing. But there is no experimental evidence for ion pairing at room temperature for a 1 molal $\mathrm{NaCl}$ solution.

There is no indication that the pseudopotential theory cannot be also employed for the simulations under supercritical conditions. As the densities of free electrons 
a

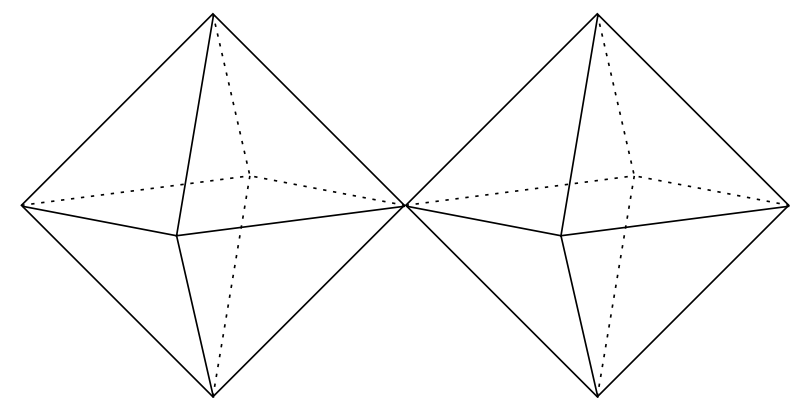

b
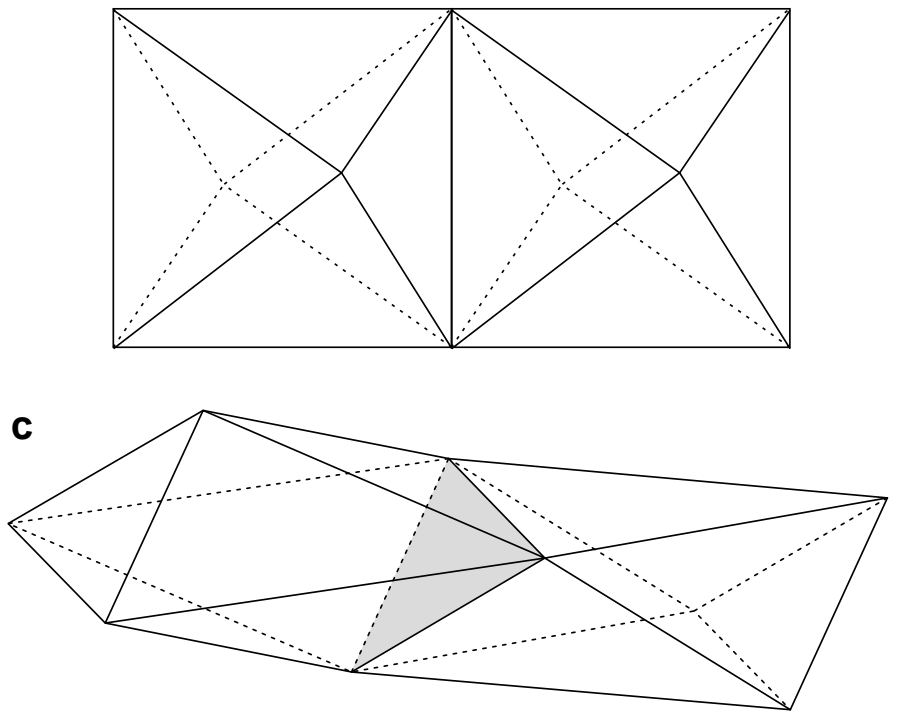

Figure 4. Solvated lithium ions with one (a), two (b), and three (c) ammonia molecules in common, calculated from a 11.64 MPM lithium-ammonia solution at $240 \mathrm{~K}$.

are abnormally low even in the concentrated metal-ammonia solutions [5], [24], treating the electron-ion interaction within the local field function approach faces some difficulties. The latter could be more pronounced under supercritical conditions. Therefore, the deviation of the indirect potential in equation (1) should be modified. Work on this subject is in progress [26].

\section{Summary and conclusions}

Molecular Dynamics simulations of supercritical ammonia are reported for the first time. The results are compared with those of neutron diffraction studies under similar conditions which provide the only experimental information on the structure of supercritical ammonia, so far. The agreement found justifies the use of the ammonia model employed not only for further simulations of supercritical pure ammonia but also of supercritical metal-ammonia solutions, at least for the time being.

In the simulation of metal-ammonia solutions, different treatments of the ionammonia potentials are necessary. If we are concerned with the solvation shells of an ion only, then single ion simulations can be employed where the electron is 
simply neglected. By comparison of the changes occurring in aqueous electrolyte solutions when going from sub- to supercritical conditions it can be concluded that the same ion-ammonia potentials can be also employed here in both cases. It has been demonstrated before that for concentrated solutions at subcritical conditions by introduction of the pseudopotential theory the electrons can be excluded from explicit consideration and classical simulations can be performed. The same procedure should be also possible under supercritical conditions, but new potentials have to be derived and calculated.

\section{Acknowledgements}

Financial support by the Russian Fund for Basic Research through Grant No. RFBR-99-03-32064 (M.K.) and by INTAS Project No. 96-1989 (M.K. and K.H.) is gratefully acknowledged. It is a pleasure to also thank the National Electronic and Computer Technology Center in Bangkok for a generous supply of computer time.

\section{References}

1. Chialvo A.A., Cummings P.T. Molecular-based modelling of water and aqueous solutions at supercritical conditions. // Adv. Chem. Phys., 1999, vol. 109, p. 115-205.

2. Bausenwein T., Bertagnolli H., David A., Goller K., Zweier H., Tödheide K., Chieux P. Structure and intermolecular interactions in fluid ammonia: An investigation by neutron diffraction at high pressure, statistical-mechanical calculations, and computer simulations. // J. Chem. Phys., 1994, vol. 101, p. 672-682.

3. Hannongbua S., Ishida T., Spohr E., Heinzinger K. Molecular Dynamics study of a lithium ion in ammonia. // Z. Naturforsch., 1988, vol. 43a, p. 572-582.

4. Hannongbua S., Kokpol S., Gurskii Z., Heinzinger K. Cluster formation in a concentrated lithium-liquid ammonia solution. A Monte Carlo study. // Z. Naturforsch., 1997, vol. 52a, p. 828-834.

5. Gurskii Z., Hannongbua S., Heinzinger K. On the structure of concentrated lithiumliquid ammonia solutions. A Molecular Dynamics study. // Mol. Phys., 1993, vol. 78, p. $461-474$.

6. Kiselev M., Kerdcharoen T., Hannongbua S., Heinzinger K. Structural properties of sub- and supercritical ammonia as studied by Molecular Dynamics simulations. // (to be published).

7. Heinzinger K. Computer simulations of metal-liquid ammonia solutions. // J. Molec. Liquids (in press).

8. Ohtaki H., Radnai T. Structure and dynamics of hydrated ions. // Chem. Rev., 1993, vol. 93, p. 1157-1204.

9. Hannongbua S. On the solvation of lithium ions in liquid ammonia: Monte Carlo simulations with a three-body potential. // Chem. Phys. Lett., 1998, vol. 288, p. 663668.

10. Kerdcharoen T., Liedl K.R., Rode B.M. A QM/MM simulation method applied to the solvation of $\mathrm{Li}^{+}$in ammonia. // Chem. Phys., 1996, vol. 211, p. 313-323. 
11. Szász Gy.I., Heinzinger K., Pálinkás G. The structure of the hydration shell of the lithium ion. // Chem. Phys. Lett., 1981, vol. 78, p. 194-196.

12. Hannongbua S. Molecular Dynamics simulation of the structure of a sodium ion in liquid ammonia. // Aust. J. Chem., 1991, vol. 44., p. 447-456.

13. Heinje G., Luck W.A.P., Heinzinger K. Molecular Dynamics simulation of an aqueous $\mathrm{NaClO}_{4}$ solution. // J. Phys. Chem., 1987, vol. 91, p. 331-338.

14. Tongraar A., Hannongbua S., Rode B.M. Molecular Dynamics simulations of a potassium ion and an iodide ion in liquid ammonia. // Chem. Phys., 1997, vol. 219, p. 279290.

15. Migliore M., Fornili S. L., Spohr E., Pálinkás G., Heinzinger K. A Molecular Dynamics study of the structure of an aqueous KCl solution. // Z. Naturforsch., 1986, vol. 41a, p. 826-834.

16. Hannongbua $\mathrm{S}$. The role of nonadditive effects in the first solvation shell of $\mathrm{Na}^{+}$and $\mathrm{Mg}^{2+}$ in liquid ammonia: Monte Carlo studies including three-body corrections. // J. Chem. Phys., 1997, vol. 106, p. 6076-6081.

17. Dietz W., Riede W.O., Heinzinger K. Molecular Dynamics simulation of an aqueous $\mathrm{MgCl}_{2}$ solution. // Z. Naturforsch., 1982, vol. 37a, p. 1038-1048.

18. Sidhisoradej W., Hannongbua S., Ruffolo D. Three-body effects in calcium(II)ammonia solutions: Molecular Dynamics simulations. // Z. Naturforsch., 1998, vol. 53a, p. 208-216.

19. Probst M.M., Radnai T., Heinzinger K., Bopp P., Rode B.M. Molecular Dynamics and X-ray investigation of an aqueous $\mathrm{CaCl}_{2}$ solution. // J. Phys. Chem., 1985, vol. 89, p. $753-759$.

20. Enderby J.E., Cummings S., Herdman G.J., Neilson G.W., Salomon P.S., Skipper N. Diffraction and the study of aqua ions. // J. Phys. Chem., 1987, vol. 91, p. 5851-5858.

21. Driesner T., Seward T.M., Tironi I.G. Molecular Dynamics simulation study of ionic hydration and ion association in dilute and 1 molal aqueous sodium chloride solutions from ambient to supercritical conditions. // Geochim. Cosmochim. Acta, 1998, vol. 62, p. 3095-3107.

22. Lee S.H., Cummings P.T. Molecular Dynamics simulation of limiting conductances for $\mathrm{LiCl}, \mathrm{NaBr}$, and $\mathrm{CsBr}$ in supercritical water. // J. Chem. Phys., 2000, vol. 112, p. 864-869.

23. Szász Gy.I., Heinzinger K. Hydration shell structures in a LiI solution at elevated temperature and pressure: A Molecular Dynamics study. // Earth Planet. Sci. Lett., 1983, vol. 64 , p. $163-167$.

24. Gurskii Z., Kushaba V., Hannongbua S., Heinzinger K. On unusually strong temperature dependences of interatomic potentials in metal-ammonia solutions. // Metal Phys. Adv. Techn., 1995, vol. 17, p. 62-67.

25. Deng Z., Martyna G.J., Klein M.L. Quantum simulation studies of metal-ammonia solutions. // J. Chem. Phys., 1994, vol. 100, p. 7590-7601.

26. Gurskii Z., Kiselev M., Hannongbua S., Heinzinger K. Molecular Dynamics simulations of supercritical concentrated metal-ammonia solutions. // (in preparation). 


\title{
Моделювання методом молекулярної динаміки надкритичного аміаку та розчинів метал-аміак
}

\author{
С.Ганнонґбуа ${ }^{1}$, М.Кісєльов ${ }^{2}$, К.Гайнцінгер ${ }^{3}$
}

1 Відділення хімії, факультет природничих наук, університет м.Чулалонгкорн, Бангкок 10330, Тайланд

2 Інститут хімії розчинів Російської академії наук, 153045 Іваново, Росія

3 Інститут хімії Макса Планка (Інститут Отто Гана), D-55020 Майнц, Німеччина

Отримано 3 березня 2000 р.

Вперше представлені результати моделювання методом молекулярної динаміки аміаку в надкритичному стані. Встановлено якісне узгодження з дослідженнями за дифракцією нейтронів, які є єдиним експериментальним свідченням про структуру аміаку у надкритичному стані. На основі відомих даних про водні розчини електролітів обговорюється питання про те, в який спосіб необхідно модифікувати потенціали, що описують взаємодії іон-аміак у розведених та концентрованих розчинах металів у аміаку, з метою їх застосування у моделюванні аміаку в надкритичному стані.

Ключові слова: метод молекулярної динаміки, водні розчини електролітів, аміак в надкритичному стані, розчини металів у аміаку

PACS: $61.20 . J, 61.20 . \mathrm{Qg}, 71.15 . P d$ 